\title{
Pneumomediastinum, subcutaneous emphysema, and pneumothorax after a pulmonary function testing in a patient with bleomycin-induced interstitial pneumonitis*
}

Pneumomediastino, enfisema subcutâneo e pneumotórax após prova de função pulmonar em paciente com pneumopatia intersticial por bleomicina

\author{
Mariana Sponholz Araujo, Frederico Leon Arrabal Fernandes, Fernando Uliana Kay, \\ Carlos Roberto Ribeiro Carvalho
}

\begin{abstract}
Spontaneous pneumomediastinum is an uncommon event, the clinical picture of which includes retrosternal chest pain, subcutaneous emphysema, dyspnea, and dysphonia. The pathophysiological mechanism involved is the emergence of a pressure gradient between the alveoli and surrounding structures, causing alveolar rupture with subsequent dissection of the peribronchovascular sheath and infiltration of the mediastinum and subcutaneous tissue with air. Known triggers include acute exacerbations of asthma and situations that require the Valsalva maneuver. We described and documented with HRCT scans the occurrence of pneumomediastinum after a patient with bleomycin-induced interstitial lung disease underwent pulmonary function testing. Although uncommon, the association between pulmonary function testing and air leak syndromes has been increasingly reported in the literature, and lung diseases, such as interstitial lung diseases, include structural changes that facilitate the occurrence of this complication.
\end{abstract}

Keywords: Mediastinal emphysema; Subcutaneous emphysema; Spirometry; Bleomycin.

\section{Resumo}

0 pneumomediastino espontâneo é um evento incomum, cujo quadro clínico inclui dor pleurítica retroesternal, enfisema subcutâneo, dispneia e disfonia. 0 mecanismo fisiopatológico implicado é o surgimento de uma diferença de pressão entre os alvéolos e estruturas adjacentes, ocasionando ruptura alveolar com posterior dissecção da bainha peribroncovascular e infiltração do mediastino e do tecido subcutâneo pelo ar. Desencadeantes conhecidos incluem exacerbação aguda de asma e situações que exigem a realização de manobra de Valsava. Descrevemos e documentamos por imagens tomográficas a ocorrência de pneumomediastino após a realização de prova de função pulmonar em um paciente com pneumopatia intersticial induzida por bleomicina. Apesar de incomum, a associação entre provas de função pulmonar e síndromes de vazamento de ar tem sido relatada cada vez mais na literatura, e doenças pulmonares, como as pneumopatias intersticiais, contemplam alterações estruturais que facilitam a ocorrência da complicação.

Descritores: Enfisema mediastínico; Enfisema subcutâneo; Espirometria; Bleomicina.

\section{Introduction}

Spontaneous pneumomediastinum is an uncommon event that primarily affects young males. It is classified as primary or secondary on the basis of the presence or absence of underlying lung disease predisposing to the event. Its clinical picture includes retrosternal chest pain (most common symptom), subcutaneous emphysema, dyspnea, dysphagia, dysphonia, asthenia, and the classical sign of Hamman's crunch (a crepitant sound that varies with the heartbeat on auscultation of the precordium). ${ }^{(1,2)}$ In most cases, it is possible to identify a triggering event, such as acute exacerbations of asthma. Other known triggers include those related to the Valsalva maneuver, such as strenuous exercise, weight lifting, inhalation

\footnotetext{
* Study carried out in the Department of Pulmonology, Heart Institute, University of São Paulo School of Medicine Hospital das Clínicas, and in the São Paulo Cancer Institute, São Paulo, Brazil.

Correspondence to: Mariana Sponholz Araujo. Rua Antônio Pietruza, 266, apto. 181, Portão, CEP 80610-320, Curitiba, PR, Brasil. Tel. 5511 98502-4275. E-mail: mari_sponholz@yahoo.com.br Financial support: None.
}

Submitted: 9 August 2012. Accepted, after review: 30 November 2012. 
of illicit drugs, cough, forced evacuation, and labor, as well as vomiting, respiratory infections, foreign body aspiration, and barotrauma. ${ }^{(1-5)}$

The disease usually follows a benign, selflimiting course. ${ }^{(1,2)}$ Treatment is supportive, consisting of using painkillers, resting, and avoiding maneuvers that generate an increase in transpulmonary pressure, such as the Valsalva maneuver and spirometry. ${ }^{(6)}$

\section{Case report}

A 50-year-old male patient underwent orchiectomy for testicular swelling and an increased alpha-fetoprotein level. The anatomopathological diagnosis was testicular embryonal carcinoma. In the staging evaluation, chest CT showed lung metastases. The patient was started on chemotherapy with cisplatin, etoposide, and bleomycin (cumulative dose at the end of the course, $300 \mathrm{lU}$ ). During treatment, the patient had an episode of febrile neutropenia and received granulocyte colonystimulating factor (G-CSF) at that time.

Three months after the start of chemotherapy, the patient had a medical visit in which he complained of rapidly progressive dyspnea, presenting with hypoxemia $\left(\mathrm{SpO}_{2}=87 \%\right)$ and crackles at both lung bases. An HRCT scan (Figure 1) showed diffuse, relatively symmetric, reticular lung opacities in a peripheral and sometimes peribronchovascular distribution, predominantly at the lung bases, associated with irregular

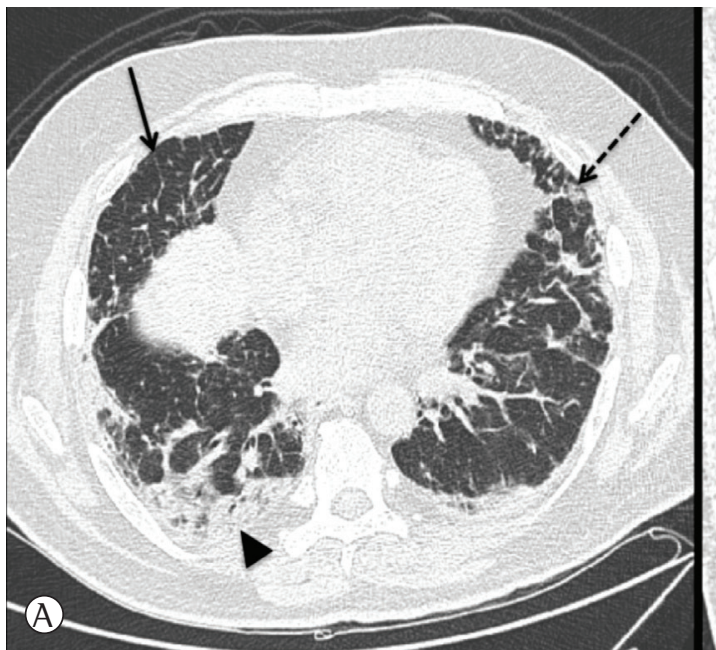

interlobular septal thickening, in addition to some foci of consolidation and areas of ground-glass opacity, bilaterally distributed, predominantly in the subpleural regions. A presumptive diagnosis of bleomycin-induced interstitial pneumonitis was made, and corticosteroid treatment was started. The patient underwent pulmonary function testing (PFT), which revealed severe restrictive lung disease and markedly reduced DLCO.

Two days after undergoing PFT, the patient presented to the emergency room with significantly worsened dyspnea. Physical examination revealed tachycardia (HR, $110 \mathrm{bpm}$ ), tachypnea (RR, 28 breaths/min), and hypoxemia ( $\mathrm{SpO}_{2}=75 \%$ ), as well as subcutaneous emphysema in the right cervical region. Lung auscultation revealed decreased breath sounds in the lower thirds and crackles at both lung bases. Laboratory tests revealed leukocytosis $\left(17,040\right.$ cells $\left./ \mathrm{mm}^{3}\right)$ with a shift to myelocytes, thrombocytopenia, an elevated level of nitrogenous compounds, and an increased level of C-reactive protein $(43.9 \mathrm{mg} / \mathrm{dL})$.

A chest $X$-ray (Figure 2) allowed the visualization of pneumomediastinum and subcutaneous emphysema, with a small pneumothorax and an increase in ground-glass opacities. The same changes were seen on HRCT (Figure 3), which showed extensive pneumomediastinum and subcutaneous emphysema, as well as a significant increase in reticular opacities and areas of ground-glass opacity, compared with the initial examination. The patient was started on treatment for an

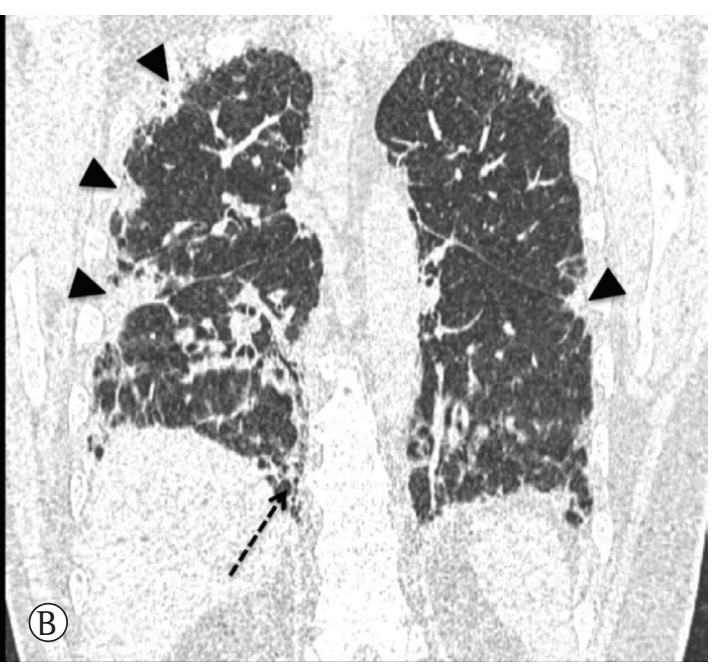

Figure 1 - In A, axial HRCT scan showing reticular opacities (dashed arrow) associated with irregular interlobular septal thickening (solid arrow), as well as foci of consolidation and areas of ground-glass opacity (arrowhead), bilaterally distributed, predominantly in the subpleural regions. In B, coronal HRCT scan showing the distribution of those changes along the longitudinal axis of both lungs, with a slight basal predominance. 


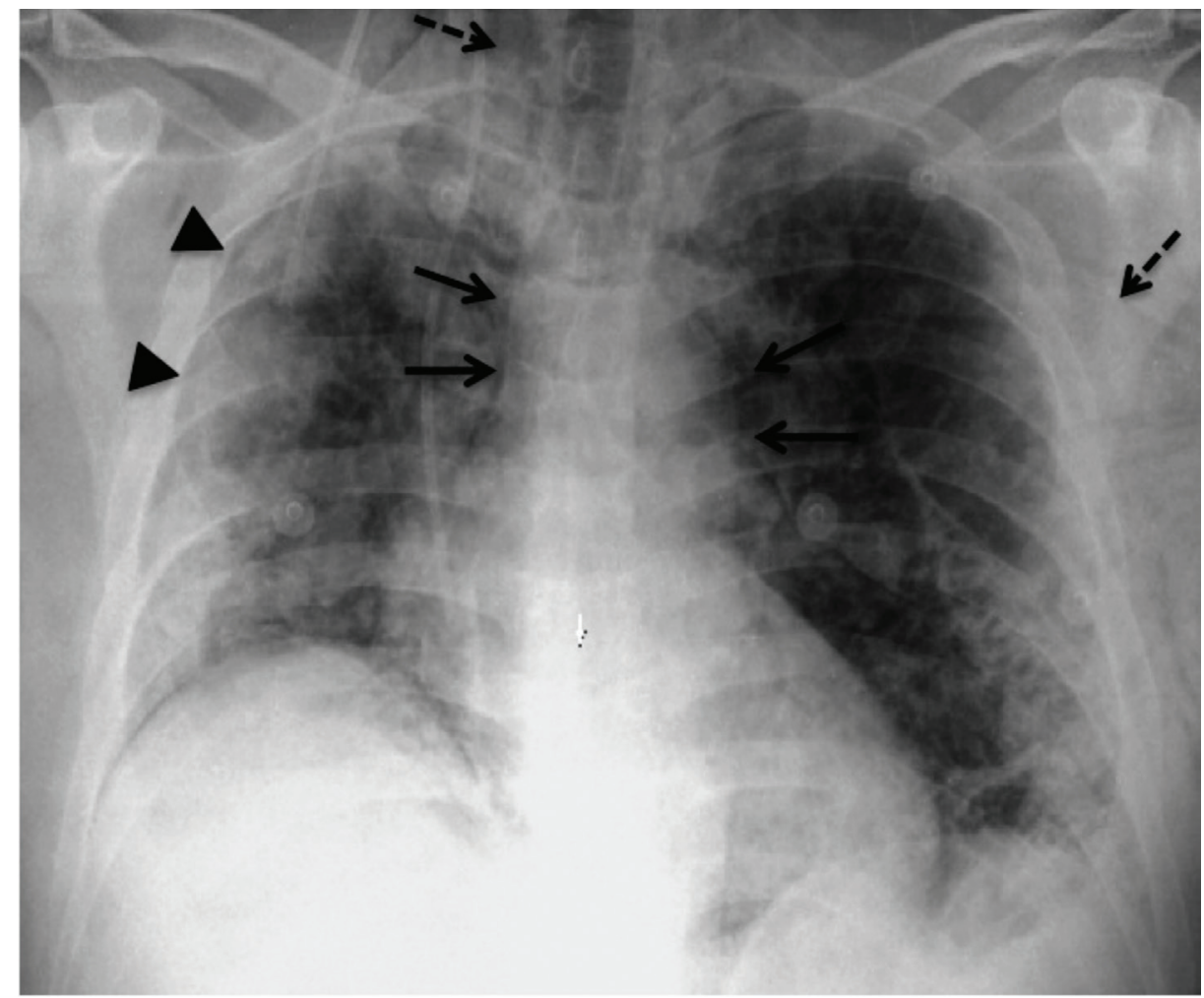

Figure 2 - (Front view) chest X-ray showing an air-density band around the mediastinum (arrows), characterizing pneumomediastinum, which extends to the cervical region and chest wall, dissecting along the fibers of the pectoral muscles (dashed arrow). Note the extensive involvement of the lungs by areas of consolidation and reticular opacities, distributed in the lung periphery, especially on the right side, where one can also see a small pneumothorax (arrowheads).

infectious etiology (piperacillin/tazobactam) and progression of interstitial disease (methylprednisolone, $1 \mathrm{mg} / \mathrm{kg}$ ). The patient continued to have fever despite further antibiotic therapy (vancomycin and sulfamethoxazole/trimethoprim were added) and developed respiratory failure requiring orotracheal intubation, mechanical ventilation, and chest tube drainage. His acute renal failure worsened, and he could not tolerate dialysis. The patient died from septic shock seven days admission.

\section{Discussion}

The pathophysiological mechanism involved in the genesis of pneumomediastinum is the emergence of a pressure gradient between the alveoli and surrounding structures that, upon reaching a critical level, causes alveolar rupture with an air leak into the interstitium, causing interstitial emphysema. The air dissects along the bronchovascular bundle (Figures $3 \mathrm{~A}$ and $3 \mathrm{~B}$ ) and, since the pressure is always lower in the mediastinum than in the lung parenchyma, the air tends to move toward the hilum and spread through the mediastinum (Figure 3C). Because of the contiguity between the fasciae, the air can reach the subcutaneous cellular tissue (Figures $3 \mathrm{~A}$ and 3D) and the peritoneum. When mediastinal pressure rises abruptly and decompression by alternative pathways is insufficient to relieve pressure, there can be rupture of the mediastinal pleura and the development of pneumothorax (Figure 3D). ${ }^{(2)}$

The Brazilian Journal of Pulmonology has recently published a letter to the editor ${ }^{(7)}$ describing a case of spontaneous pneumomediastinum and reporting, among other findings, pneumorrhachis, which is extremely rare. However, in that case, no imaging findings of dissection of air along the bronchovascular bundle were found. In a case report of pneumomediastinum in a bone marrow transplant recipient, some HRCT findings were similar to those of the present case, although they were of lesser magnitude and there was no pneumothorax. ${ }^{(8)}$ 


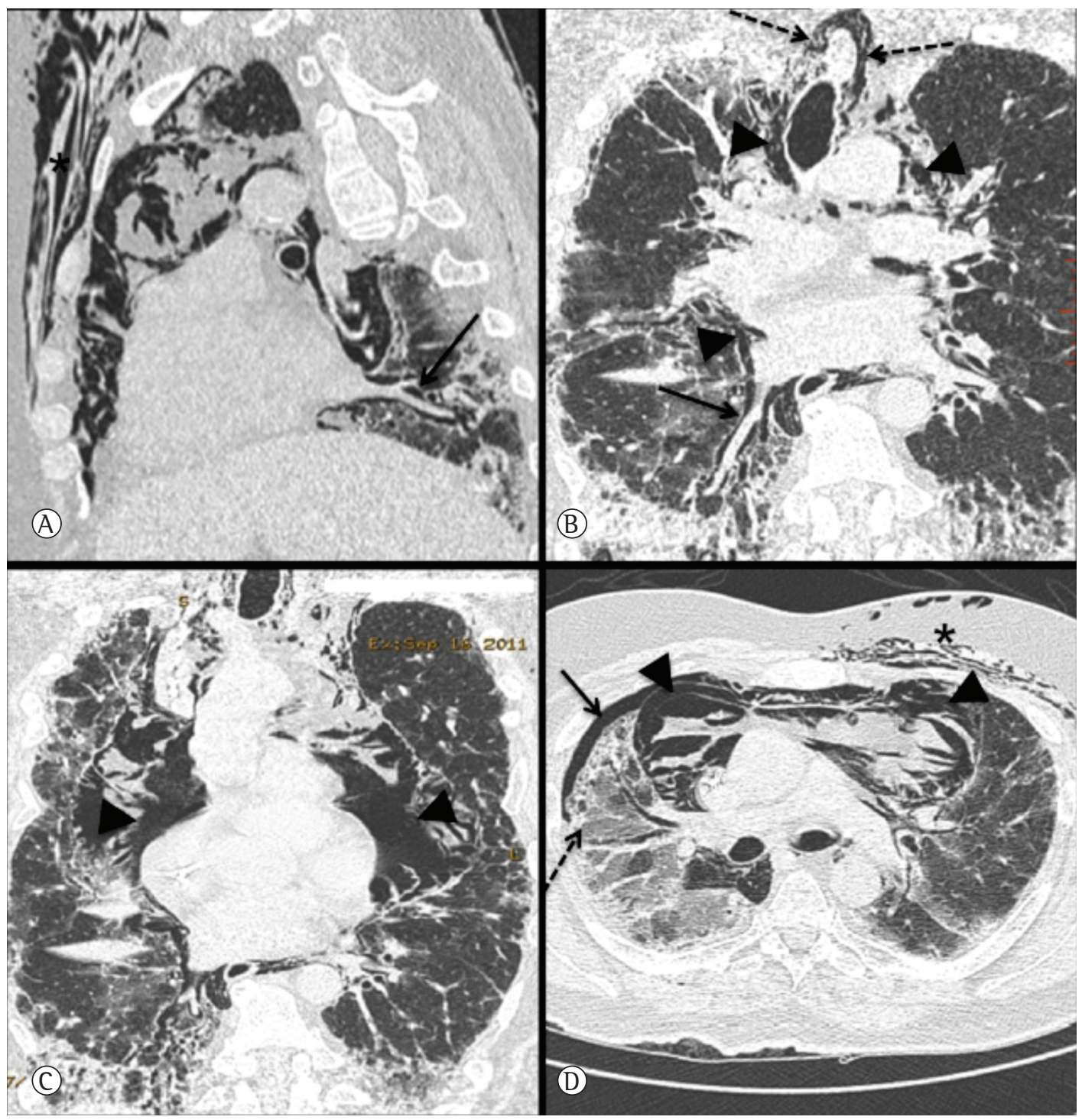

Figure 3 - In A, oblique sagittal reformatted HRCT scan showing air dissecting within the lung interstitium along the right inferior pulmonary vein (arrow) and entering the mediastinum. In B, curved coronal reformatted HRCT scan showing the upward path of the air around the right inferior pulmonary vein (arrow) into the pneumomediastinum (arrowheads). Note the integration between the pneumomediastinum and the cervical emphysema (dashed arrows). In C, curved coronal reformatted HRCT scan showing the large amount of air that dissects along the mediastinal fat planes and pneumomediastinum (arrowheads). In D, axial HRCT scan showing pneumomediastinum (arrowheads) associated with chest wall emphysema (asterisk, also found in A). Note also a small right pneumothorax (arrow), as well as reticular lung opacities and areas of groundglass opacity (dashed arrow).

This chain of events was described by Macklin \& Macklin in the 1940s. ${ }^{(3)}$ Those authors demonstrated that most air leak syndromes did not result from rupture of subpleural bullae, but rather from alveolar rupture. In addition, they introduced the concept that the presence of positive pressure within the alveoli is not necessary for rupture to occur. What is essential is the pressure gradient between the alveolus and the perivascular sheath of the adjacent septum. A very negative pressure in the interstitial space could therefore lead to alveolar rupture even without the occurrence of extreme positive alveolar pressures. For this reason, intense respiratory efforts, adjacent atelectasis, and low intravascular pressure could be involved in the development of these syndromes. ${ }^{(3)}$ 
There have been reports of pneumomediastinum related to PFT. ${ }^{(4,9-11)} \ln 1973$, the first of such reports described a previously healthy 23-year-old medical student who developed extensive pneumomediastinum and subcutaneous emphysema after undergoing PFT. ${ }^{(4)}$

In spirometry, the patient is instructed to inhale up to total lung capacity, hold his or her breath, and exhale vigorously. ${ }^{(10)}$ When the patient inhales, there is a decrease in intrathoracic pressure, an increase in alveolar air volume, and an increase in venous return, resulting in increased pulmonary vein diameter. Therefore, there is no pressure gradient in the interstitial space, since all compartments elongate and increase in diameter symmetrically. However, when the patient "holds his or her breath", there is venous stasis, resulting in decreased pulmonary venous filling and vessel lumen reduction, allowing the emergence of the pressure gradient necessary to cause alveolar rupture. ${ }^{(3)}$

Subsequent reports have documented pneumomediastinum as a complication of PFT associated with extremely different underlying lung diseases, such as rheumatic diseases with interstitial lung involvement. ${ }^{(11)}$ In these situations, there is a summation of the aforementioned pressure changes induced during the test, the existence of inflammation combined with increased elastic recoil as seen with fibrosis, and a collapse of adjacent regions, making the lung vulnerable to segmental hyperdistension and to the emergence of a pressure gradient. ${ }^{(3)}$ We believe that this is the mechanism also applies in the present case.

When reporting the case of a healthy medical student who developed pneumomediastinum after use of marijuana, one group of authors understood that the event was caused by the fact that the young man performed various Valsalva-like maneuvers (holding his breath at maximal inhalation against a partially closed or fully closed glottis) to prolong the effect of the drug. ${ }^{(12)}$ The Valsalva maneuver is a factor classically related to air leak syndromes because it generates increased intrapulmonary pressure. $(3,4,12)$ Therefore, labor and forced evacuation are associated with reports of pneumomediastinum. ${ }^{(3)}$

As mentioned previously, pneumomediastinum usually follows a benign, self-limiting course. However, this apparent benignity should be regarded with caution, since, in patients with underlying lung diseases, the existence of air leak syndromes is associated with greater severity. It is known that this syndrome can be associated with the spread of infections and the release of inflammatory mediators. In addition, it can result in the feared air-block syndrome (a condition in which the presence of air in the interstitium and mediastinum does not find a way out, culminating in the generation of large pressures on the mediastinum, which affects circulation by compressing the vessels and the heart and prevents lung inflation and deflation). ${ }^{(2)}$

In the present case, it is possible that the pneumomediastinum acted as a contributing factor to the fatal outcome because it facilitated the spread of infection and the perpetuation of inflammation, but without acting as a determinant of death, which was related to the interstitial lung disease and the severe, superimposed infectious process. In addition, it is of note that, in the present case, there was no indication for specific treatment for pneumomediastinum, such as mediastinotomy. This type of procedure would only be beneficial in cases of hypertensive pneumomediastinum, which are rare. ${ }^{(13)}$

Because PFT is often performed in patients with acute chronic respiratory disease, its association with air leak syndromes should be studied and reported.

The most common form of pulmonary toxicity associated with bleomycin is subacute progressive pulmonary fibrosis. Other less common lesions include organizing pneumonia, hypersensitivity pneumonia, and acute chest pain syndrome. It occurs more frequently in elderly subjects, with higher cumulative doses of the medication, renal failure, use of oxygen (especially when high $\mathrm{FiO}_{2}$ is used), combination of other chemotherapeutic agents (such as cisplatin and gemcitabine), thoracic radiation therapy, and use of G-CSF. (14) Bleomycin-induced interstitial pneumonitis is understood as a causative factor for the occurrence of pneumomediastinum in the current literature, on the basis of two studies that reported three cases in which this association occurred. ${ }^{(15,16)}$ Curiously, in at least two of those cases, PFT was performed before the development of pneumomediastinum; however, those authors did not infer a causal relationship between PFT and the occurrence of the complication. ${ }^{(16)}$ It is evident that interstitial pneumonitis includes previously mentioned factors, such as local inflammation and alveolar collapse, that facilitate the development of pneumomediastinum. Under 
these conditions, there can be hyperinflation of adjacent regions, increased elastic recoil, and reduced lung compliance, predisposing to the emergence of an increased pressure gradient, but it seems pertinent to investigate what role PFT might also have played in those reports.

In the present case, because of the strong temporal correlation between the patient having undergone PFT and the occurrence of pneumomediastinum, in addition to the pathophysiological rationale, we consider that the "trigger" for the occurrence of air leak was the patient having undergone the test, although it is undeniable that the presence of bleomycin-induced interstitial pneumonitis created a predisposition to the event.

The present report and a review of cases in the literature suggest the need for caution and proper orientation of patients with bleomycin-induced interstitial pneumonitis who perform PFT maneuvers.

\section{References}

1. Abolnik 1, Lossos 1S, Breuer R. Spontaneous pneumomediastinum. A report of 25 cases. Chest. 1991;100(1):93-5. http://dx.doi.org/10.1378/chest.100.1.93 PMid:1824034

2. lyer VN, Joshi AY, Ryu JH. Spontaneous pneumomediastinum: analysis of 62 consecutive adult patients. Mayo Clin Proc. 2009;84(5):417-21. PMid:19411438 PMCid:2676124

3. Macklin MT, Macklin CC. Malignant interstitial emphysema of lungs and mediastinum as important occult complications in many respiratory diseases and other conditions: interpretation of clinical literature in the light of laboratory experiment. Medicine. 1944;23:281-358. http://dx.doi.org/10.1097/00005792-194412000-00001

4. Varkey B, Kory RC. Mediastinal and subcutaneous emphysema following pulmonary function tests. Am Rev Respir Dis. 1973;108(6):1393-6. PMid:4751724

5. Campillo-Soto A, Coll-Salinas A, Soria-Aledo V, BlancoBarrio A, Flores-Pastor B, Candel-Arenas M, et al. Spontaneous pneumomediastinum: descriptive study of our experience with 36 cases [Article in Spanish].
Arch Bronconeumol. 2005;41(9):528-31. http://dx.doi. org/10.1157/13078656 PMid:16194517

6. Macia 1, Moya J, Ramos R, Morera R, Escobar l, Saumench J, et al. Spontaneous pneumomediastinum: 41 cases. Eur J Cardiothorac Surg. 2007;31(6):1110-4. http:// dx.doi.org/10.1016/j.ejcts.2007.03.008 PMid:17420139

7. Alves GR, Silva RV, Corrêa JR, Colpo CM, Cezimbra HM, Haygert CJ. Spontaneous pneumomediastinum (Hamman's syndrome). J Bras Pneumol. 2012;38(3):404-7. http://dx.doi.org/10.1590/S1806-37132012000300018 PMid:22782613

8. Dias OM, Cavalcanti Coelho DL, de Carvalho CR. Interstitial emphysema leading to pneumomediastinum in a bone marrow transplant patient. Am J Respir Crit Care Med. 2013;188(3):e4. doi: 10.1164/rccm.201203-0385IM..

9. Manço JC, Terra-Filho J, Silva GA. Pneumomediastinum, pneumothorax and subcutaneous emphysema following the measurement of maximal expiratory pressure in a normal subject. Chest. 1990;98(6):1530-2. http://dx.doi. org/10.1378/chest.98.6.1530 PMid:2245704

10. Krasnick J. Pneumomediastinum following spirometry. Chest. 2001;120(3):1043. http://dx.doi.org/10.1378/ chest.120.3.1043 PMid:11555557

11. Jun JB, Song SY. The development of pneumomediastinum after pulmonary function testing in a patient with systemic sclerosis. Rheumatol lnt. 2007;27(11):1097-8. http:// dx.doi.org/10.1007/s00296-007-0369-7 PMid:17562046

12. Miller WE, Spiekerman RE, Hepper NG. Pneumomediastinum resulting from performing Valsalva maneuvers during marihuana smoking. Chest. 1972;62(2):233-4. http:// dx.doi.org/10.1378/chest.62.2.233 PMid:5050235

13. Herlan DB, Landreneau RJ, Ferson PF. Massive spontaneous subcutaneous emphysema. Acute management with infraclavicular "blow holes". Chest. 1992;102(2):503-5. http://dx.doi.org/10.1378/chest.102.2.503 PMid:1340766

14. Jules-Elysee K, White DA. Bleomycin-induced pulmonary toxicity. Clin Chest Med. 1990;11(1):1-20. PMid:1691067

15. White DA, Stover DE. Severe bleomycin-induced pneumonitis. Clinical features and response to corticosteroids. Chest. 1984;86(5):723-8. http://dx.doi. org/10.1378/chest.86.5.723 PMid:6207992

16. Sikdar T, MacVicar D, Husband JE. Pneumomediastinum complicating bleomycin related lung damage. Br J Radiol. 1998;71(851):1202-4. PMid:10434917 
Pneumomediastinum, subcutaneous emphysema, and pneumothorax after a pulmonary function testing in a patient with bleomycin-induced interstitial pneumonitis

\section{About the authors}

Mariana Sponholz Araujo

Pulmonologist. Department of Pulmonology, Heart Institute, University of São Paulo School of Medicine Hospital das Clínicas, São Paulo, Brazil.

\section{Frederico Leon Arrabal Fernandes}

Physician in Charge of the Pulmonary Function Laboratory, São Paulo Cancer Institute; and Attending Physician. Heart Institute, University of São Paulo School of Medicine Hospital das Clínicas, São Paulo, Brazil.

\section{Fernando Uliana Kay}

Radiologist. Imaging Department, University of São Paulo School of Medicine Hospital das Clínicas, São Paulo, Brazil.

\section{Carlos Roberto Ribeiro Carvalho}

Tenured Associate Professor. Department of Pulmonology, Heart Institute, University of São Paulo School of Medicine Hospital das Clínicas, São Paulo, Brazil. 